\title{
INJERTO DE TEJIDO CONECTIVO OBTENIDO DE ZONA DE TUBEROSIDAD: REPORTE DE CASO CLÍNICO
}

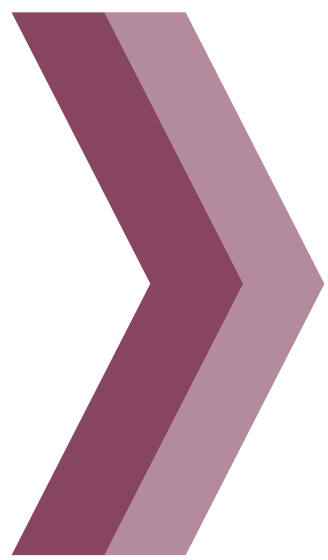

\author{
CONJECTIVE TISSUE \\ GRAFTING OBTAINED \\ FROM TUBEROSITY AREA: \\ CLINICAL CASE REPORT
}

Jaime Bárcena Taco ${ }^{1}$ Alejandro Aldana Cáceres ${ }^{2}$

1. Magíster en Docencia Universitaria y Gestión Educativa Docente Escuela de Odontología de la Universidad Jorge Basadre Grohmann

2. Doctor en Ciencias de la Salud, Docente Escuela de Odontología de la Universidad Jorge Basadre Grohmann

\section{RESUMEN}

El manejo adecuado de los tejidos blandos periimplantarios es sumamente importante para obtener una respuesta además de funcional, estética; siendo el sector anterior el más expuesto durante la actividad diaria al hablar, sonreír y en la vida cotidiana, requiere mayor atención. El presente caso clínico muestra la técnica de injerto de tejido epitelioconectivo des-epitelizado, tomado de la zona edéntula de la tuberosidad, para corregir un defecto vestibular horizontal y vertical sobre una restauración soportada por implante. La obtención del injerto de la tuberosidad es sencilla, no genera mayor trauma y puede considerarse incluso de un postoperatorio más cómodo para el paciente, no requiere el uso de una placa palatina como en los casos de obtenerse del paladar. Además, podemos luego de una volumetría adecuada decidir extraer mayor cantidad de tejido con el beneficio de tener una mayor cobertura.

PALABRAS CLAVES: implante dental, injerto, epitelio, conectivo.

\begin{abstract}
The proper management of peri-implant soft tissues is extremely important to obtain a response in addition to functional, aesthetic; being the previous sector the most exposed during the daily activity when talking, smiling and in everyday life, requires more attention. The present clinical case shows the technique of epithelial-de-epithelial connective tissue graft, taken from the edentulous zone of the tuberosity, to correct a vestibular horizontal and vertical defect on a restoration supported by an implant. The obtaining of the graft of the tuberosity is simple, it does not generate more trauma and it can even be considered a more comfortable postoperative for the patient, it does not require the use of a palatal plate as in the cases of obtaining from the palate. In addition, after a suitable volumetry we can decide to extract more tissue with the benefit of having a greater coverage.
\end{abstract}

KEY WORDS: dental implant, graft, epithelium, connective. 


\section{INTRODUCCIÓN}

El manejo de defectos del tejido gingival asociados a pérdida de soporte óseo es cada vez más necesario debido a la demanda estética que no solo requiere reponer dientes, sino que conlleva la urgencia de solucionar defectos estructurales mediante técnicas con injerto de tejido conectivo que nos ayuden estabilizando los tejidos blandos y permitan mejorar el aspecto estético generado por el defecto; además se va contrarrestar las recesiones gingivales y por tanto una mejora del biotipo gingival con injerto de tejido conectivo des-epitelizado siendo más denso, más estable y sujeto a menor contracción durante el proceso de curación.

El defecto generado en el reborde alveolar residual se puede corregir con manejo de parte del laboratorio utilizando cerámicas que simulen el tejido gingival, pero ello no necesariamente conseguirá el resultado estético que satisfaga adecuadamente a un paciente exigente o cuando el tipo de sonrisa sea gingival o alta, dejando expuesta estructuras protésicas con una apariencia no estética, complicaciones fonéticas y de higiene. Los defectos de la zona edéntula fueron clasificados por Seibert según su grado de severidad, en defectos verticales, horizontales y la combinación de ambos. Una alternativa para corregir estos defectos es utilizar colgajos de tejido conectivo pediculado (Sclar 2003), compuesto de periostio y tejido conectivo, que juntos van a aumentar el volumen crestal. La rehabilitación implanto soportada y las prótesis fijas convencionales enfrentan inevitablemente los defectos consecuencia de la perdida de la tabla vestibular que no supera muchas veces $1 \mathrm{~mm}$, que ante una exodoncia traumática, es decir, la misma por enfermedad periodontal traerá como consecuencia crestas residuales alteradas. La reabsorción ósea reportada es de un promedio del 50\% en el ancho del reborde alveolar, asi también de 2 a $4 \mathrm{~mm}$., en altura.

Entre las técnicas de injertos de tejido conectivo, la obtención de una cantidad adecuada y en forma accesible es la que extraemos de la zona de la tuberosidad, que luego de una evaluación volumétrica puede aportarnos una cantidad generosa de tejido conectivo luego de eliminar la superficie epitelial. En el presente caso clínico se reporta el tratamiento de un defecto de la zona edéntulatipo III de Seibert, correspondiente a una perdida horizontal y vertical consecuencia de la exodoncia de las piezas $N^{\circ} 1,3-1,2$.

\section{CASO ClínICO}

Paciente de 36 años de edad, de sexo femenino, acude a la Clínica de la Especialidad de Periodoncia e Implantología de la Facultad de Ciencias de la Salud de la Universidad Nacional Jorge Basadre Grohmann (Tacna - Perú) en julio de 2017, por requerir tratamiento de restauración implanto soportada. Es referida de clínica de pregrado, con antecedente de exodoncia de piezas $N^{\circ} 1,2$ (reabsorción radicular) y 1,3 (remanente radicular)(Fig.1-2). Se realizó la historia clínica, durante la anamnesis la paciente no refiere antecedentes sistémicos, consumo de tabaco, condiciones de disfunción mandibular, ni patologías que sean contribuyentes y se deba considerar.

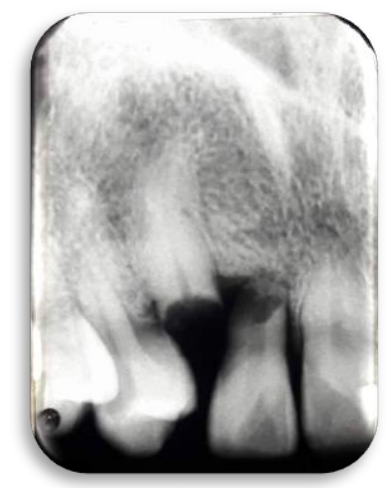

Figura 1.

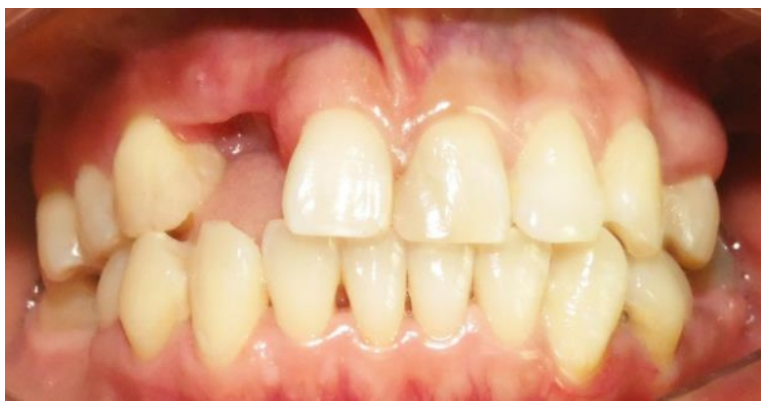

Figura 2.

Al examen clínico, es una paciente de tez trigueña, con simetría facial, sin lesiones ni adenopatías aparentes. Al examen clínico intraoral se observa leve inflamación gingival(7), obturaciones en condiciones adecuadas; se evidencia zona edéntula con disminución de espacio mesiodistal(8) entre $N^{\circ} 1,4$ y 1,1 , con reborde residual disminuido tipo III de Seibert, evidenciable al momento de sonreír, restaurado con prótesis provisional. El examen radiográfico del sector antero superior evidencia la ausencia del incisivo lateral y canino superior derecho. Al examen tomográfico con guía quirúrgica se establece diámetro y altura adecuada 
para instalar implante dental (Figura $3 a-3 b)$.

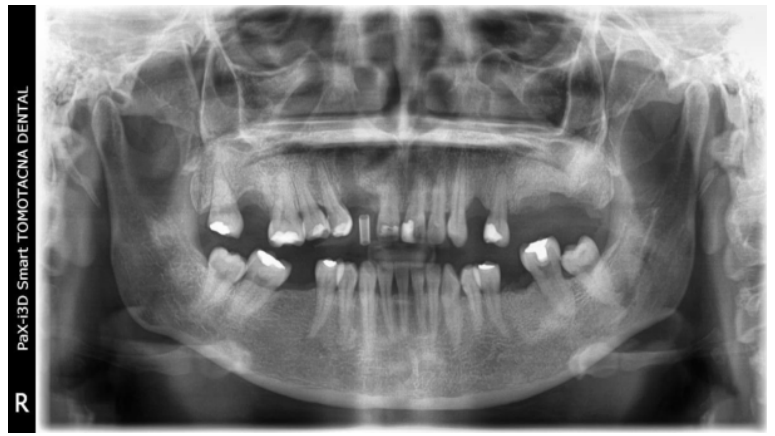

Figura 3a.

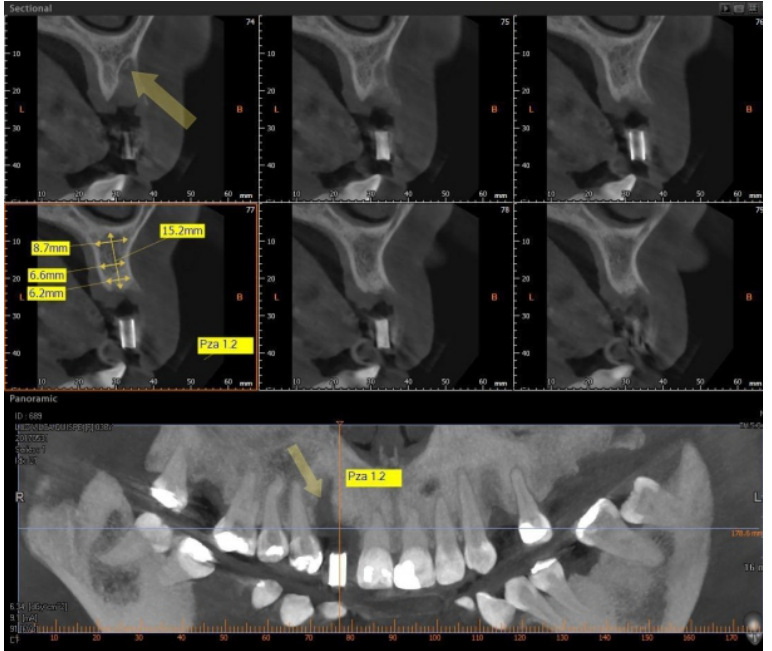

Figura 3b.

Debido a la exigencia estética del caso se planificó una segunda fase quirúrgica para instalar un cicatrizal e injerto de tejido conectivo a fin de corregir el defecto en volumen.

El paciente fue notificado de las opciones de tratamiento y luego de firmar el consentimiento informado se procedió a realizar los siguientes tratamientos:

FASE I (Educación y motivación, control de biofilmdental, instrucciones de higiene oral, raspado y alisado radicular). FASE 2 (Colocación de implante dental en espacio edéntulo). FASE 3 (Colocación de tornillo cicatrizal e injerto de tejido conectivo en la zona vestibular para corregir el defecto). FASE 4 Provisionalización con un pilar atornillado para mejorar la conformación gingival e instalación de corona metal cerámica.

\section{Procedimiento quirúrgico para implante:}

La zona a operar se infiltró con anestesia local, lidocaína2\% más epinefrina 1:80000(Lidocaina ${ }^{\circledR}$ ). Para la instalación del implante se realizó un colgajo a espesor total, con incisión supracrestal levemente a palatino y sin descargas laterales. Se hizo uso de una guía quirúrgica para ubicar la posición óptima del implante. Se instaló el implante con un torque mayor a $30 \mathrm{~N}$, colocó tapa de cierre y se cerró el colgajo con sutura colchonero vertical.

Se diseñó una incisión sulcular a nivel vestibular y palatino del incisivo central superior y primer premolar derecho unidos por una incisión supracrestal levemente hacia palatino para luego realizar el desprendimiento del colgajo a espesor total sin descarga lateral (Fig.4), luego se procedió a realizar el protocolo de fresado para la colocación de un implante dental: se inició con la fresa lanza y luego la fresa piloto. El protocolo de fresado fue iniciado para obtener la orientación de colocación del implante dental con apoyo de una guía quirúrgica en acrílico utilizado en la tomografía diagnóstica. Se realizó el fresado requerido y la instalación del implante NovelTi de 3,75 x 13mm, con un torque $>30 \mathrm{~N}$.(Fig.5).

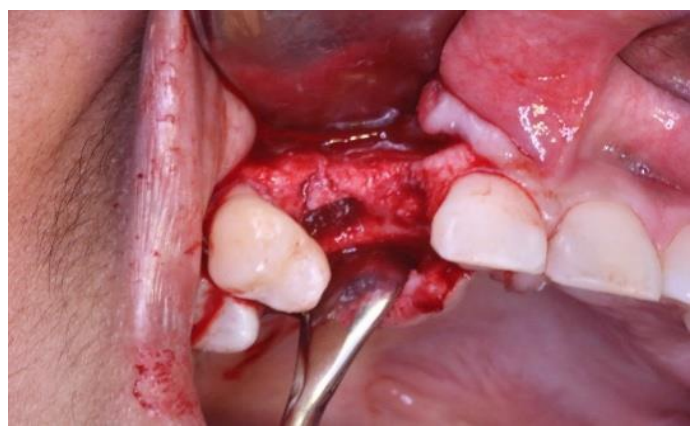

Figura 4.

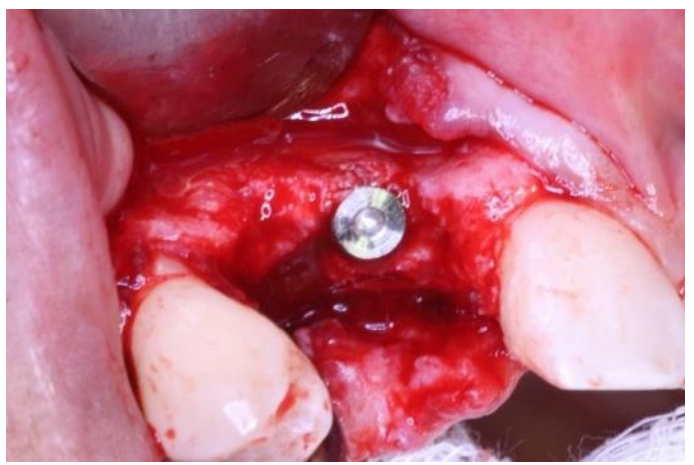

Figura 5.

Se colocó la tapa del implante y se procedió a la sutura con seda negra 4 ceros y punto tipo colchonero vertical 
(Fig. 6). Se recomendó una dieta blanda luego de la cirugía de colocación de implante dental más antiinflamatorios (diclofenaco + paracetamol cada 8 horas por 2 días) y antibioticoterapia (Amoxixilina $500 \mathrm{mg}+$ acidoclavulánico $125 \mathrm{mg}$ cada 8 horas por 6 días).

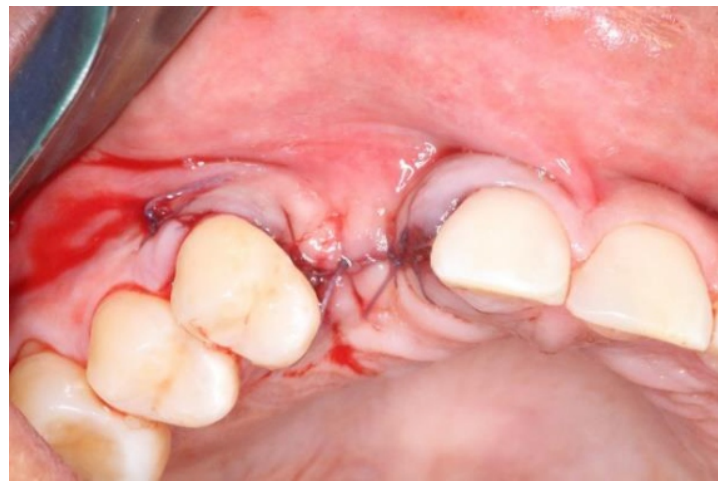

Figura 6.

\section{Seguimiento clínico}

Luego de 10 días de pos operatorio no se reportaron complicaciones y la cicatrización del tejido blando fue apropiada.

\section{Procedimiento quirúrgico para injerto de tejido conectivo}

Luego de tres meses de cicatrización se procedió a realizar un injerto de tejido epitelio-conectivo obtenido de la zona de la tuberosidad izquierda. Se realizó una incisión respetando la zona papilar extendiendo la incisión aproximadamente $8 \mathrm{~mm}$ a palatino, sin descarga lateral vestibular; se realiza el desprendimiento del colgajo a vestibular de espesor parcial hasta pasar la línea mucogingival dejando un bolsillo. Se instala el pilar cicatrizal cónico de $5 \mathrm{~mm}$., e inmediatamente se realiza el tratamiento del injerto epitelio-conectivo, utilizando la técnica de raspado mediante un bisturí $15 \mathrm{C}$ para eliminar la superficie epitelial, conservando el conectivo. Se procedió a instalar el injerto con una sutura tipo marioneta, inmovilizado el injerto; se continuó con la sutura del colgajo de tipo colchonero vertical e hilo de sutura 4 ceros de seda negra. Fig. 7a, 7b, 7c.

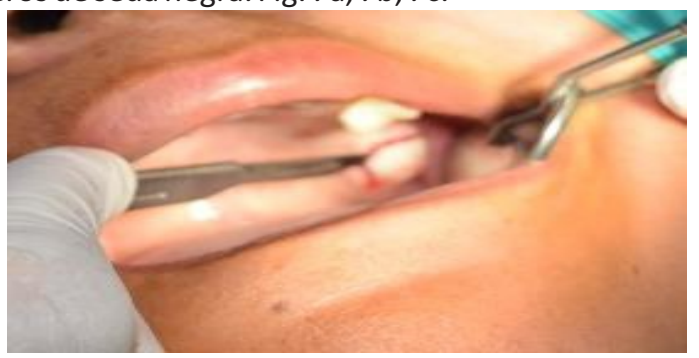

Figura 7a.

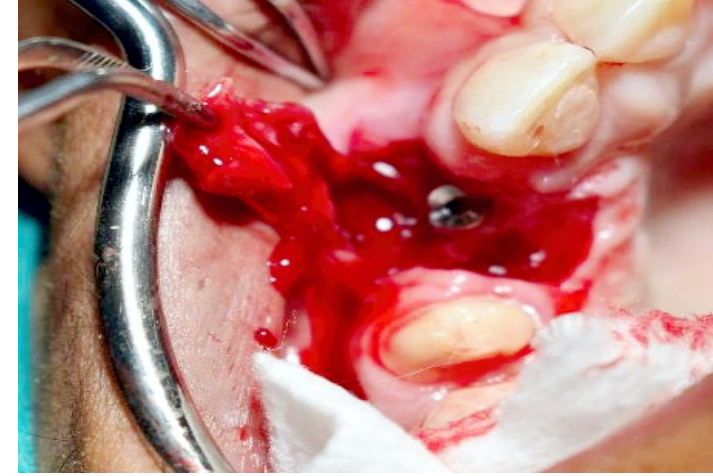

Figura 7b.

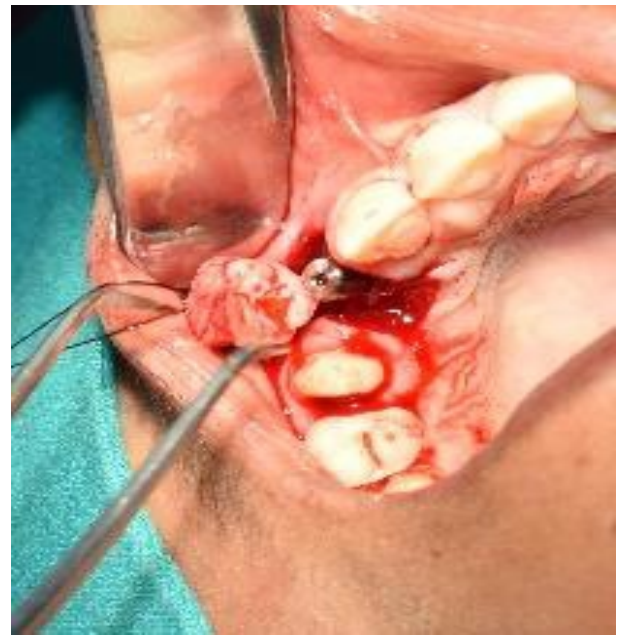

Figura 7c.

\section{Seguimiento clínico}

Luego de 10 días de post operatorio sin complicaciones, se observó un tejido en proceso de cicatrización. Posteriormente se procedió a instalar un pilar cicatrizal con corona provisional para optimizar el perfil de emergencia (Fig.8a, 8b). Con el pilar definitivo se cementó la corona metal cerámica a nivel del incisivo lateral derecho(Aún en proceso).

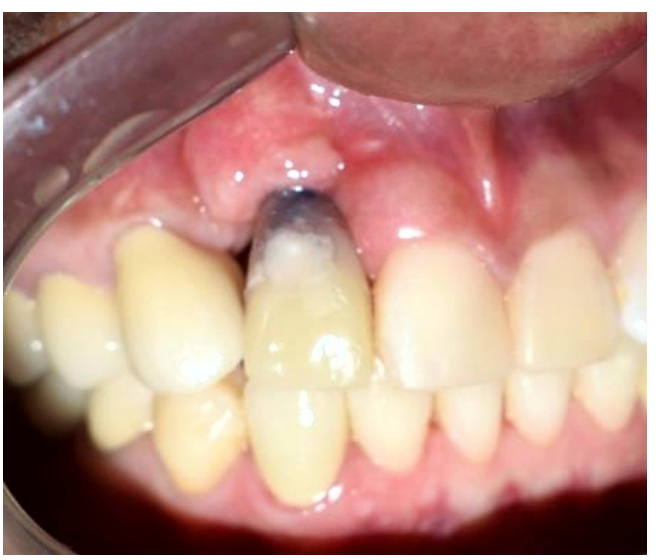

Figura 8a. 


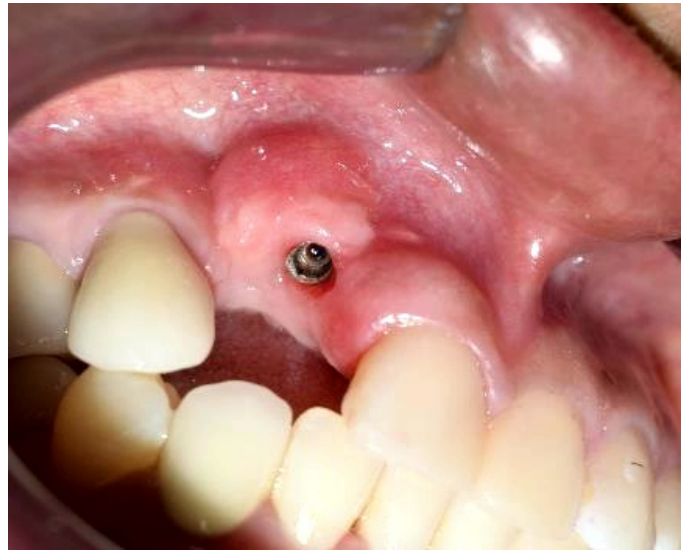

Figura 8b.

\section{DISCUSIÓN}

El resultado estético en la actualidad cada vez es de mayor prioridad, el defecto del reborde alveolar posterior a la exodoncia es inevitable; consecuentemente, la restauración protésica no podrá tener la suficiente anatomía gingival en su entorno y la expectativa no será debidamente satisfecha en condiciones óptimas.

Lo recomendable es prevenir la reabsorción de la tabla vestibular que sabemos es en sentido vestíbulo palatino hasta de un 50\%; por ello se recomienda diferentes técnicas de preservación: relleno de hueso, membrana, técnica de Socket Shield, y otras, pero no siempre se informa adecuadamente al paciente y se sigue haciendo exodoncias sin mayor criterio de preservación. Sin embargo, el objetivo de la preservación de la cresta alveolar después de la extracción dental aún no es posible evitar, pese a las diferentes técnicas todavía en uso y nuevas que van presentándose.

El defecto óseo que afecta la restauración en condiciones estéticas adecuadas puede requerir de tratamientos con injertos óseos autógenos para mejorar el defecto de la cresta; sin embargo se tiene que considerar que es posible la respuesta inadecuada debido a alguna morbilidad en la zona receptora y dadora del mismo. El injerto de tejido conectivo es un procedimiento bastante utilizado para los defectos de crestas alveolares con Seibert tipo II y III. El injerto de tejido conectivo subepitelial todavía se considera el estándar de oro.

Se concluye que el aumento de tejido blando con injerto de tejido conectivo de la zona de tuberosidad del paladar en condiciones adecuadas es un tratamiento viable y predecible para proporcionar un perfil gingival adecuado y un contorno alveolar de relleno del defecto vestibular consecuencia de la reabsorción inevitable, aún en proceso de tratamientos modernos que buscan preservar, favorece la restauración con resultados estéticos y predecibles. El post operatorio en la zona asociada al sitio del cual se obtiene el tejido epitelio-conjuntivo evoluciona sin mayores molestias, incluso menor al de una exodoncia.

\section{REFERENCIAS BIBLIOGRÁFICAS}

1. Anasane N, Chitnis D, Meshram S. Enhancing aesthetics in anterior fixed partial denture by soft tissue ridge augmentation: A clinical report. Indian Journal of Dent Edu. 2011; 4:13-16.

2. De Melo L, Neto J, Teixeira W. Application of a modified roll technique to ridge augmentation before implant surgery: A case report. Periodontol 2000. 2006; 3:49-56.

3. Sclar A. The vascularized interpositional periosteal conective tissue (VIP-CT) flap in Chicago-EEUU: Quintessence; 2003.

4. Schropp L, Wenzel A, Kostopoulos L. Bone healing and soft tissue contour changes following single-tooth extraction: a clinical and radiographic 12 month prospective study. Int J Periodontics Restor Dent. 2003; 23:313-323.

5. Araujo M, Lindhee J. Dimensional ridge alterations following tooth extraction: An experimental study in the dog. J Periodontol. 2005; 32:212-8.

6. Alonso A. Oclusión y Diagnóstico en Rehabilitación Oral. 13th ed. Buenos Aires - Argentina: Editorial Médica Panamericana; 2004.

7. The American Academy of Periodontology. Glossary of Periodontal Terms. In edición 3, editor. Chicago: The American Academy of Periodontology; 1992.

\section{Correspondencia}

Jaime Bárcena Taco

jaimebarcenataco@hotmail.com
8. Baidas L. Comparación del ancho de los dientes anteriores en ausencia congénita unilateral y bilateral de los incisivos laterales maxilares. Journal of contemporary dental practice. 2005 January; 6(1): 56-63.

9. Anusaksathien O GW. Growth factor delivery to re-engineer periodontal tissues. Curr Pharm Biotechnol. 2002; 3:129-139.

10. Santhanakrishnan M. Reconstruction of interdental papilla using autogenous bone and connective tissue grafts. Journal of Indian Society of Periodontology. 2016 Febrero; 20:4(464-467).

11. Azzi $R, T H, E D$. Root coverage and papilla reeconstruction using autogenous osseous and connective tissue grafts. Int. Journal Periodontics Restorative Dent. 2001; 21:141-7.

12. Jung R, Philip A, Annen B, al. e. Radiographic evaluation of different techniques for ridge preservation after tooth extraction. J Periodontol. 2013; 40:90-98.

13. Studer S, Naef R, Scharer P. Adjustment of localized alveolar ridge defects by soft tissue transplantation to improve mucogingival esthetics: A proposal for clinical classification and an evaluation of procedures. Quintessence Int. 1997; 28:785-805. 